\title{
Specifying the target identity of motoneurons
}

\author{
Kathryn W. Tosney, Kevin B. Hotary and Cynthia Lance-Jones
}

\section{Summary}

In the vertebrate spinal cord, motoneurons are clustered into longitudinal columns in agreement with the targets they innervate. Motoneurons within each column acquire properties early in development that ensure their axons navigate to appropriate targets, but how this target identity is specified is unknown. Recently, Tsuchida et al.(1) described the expression of putative regulatory genes within motor columns in the chicken spinal cord. Combinations of LIM-family homeobox genes differentially mark columns that project to distinct target groups. Expression precedes column formation and axon outgrowth, making these genes candidates for specifying the target identity of motoneuron groups.

Accepted

6 March 1995

\section{Motoneuron organization and projection}

Motoneurons are topographically ordered within the spinal $\operatorname{cord}^{(2-4)}$ (Fig. 1). The arrangement is hierarchical. At the finest level, motoneurons projecting to a single muscle are clustered together in a longitudinal column called a 'pool'. Pools are grouped into larger columns according to their target location. Motoneurons in the column of Terni (CT) project ventrally to sympathetic ganglia. Motor pools in the lateral motor column (LMC) project to limb muscles, while those in the medial motor column (MMC) project to axial muscles. The limb and axial columns are further subdivided along the medial-lateral axis in an intriguing agreement with the dorsal-ventral positions of their respective targets (Fig. 1). Each column has a characteristic placement along the cranial-caudal axis. This basic pattern of five spatially discrete columns with five distinct target preferences is found in many vertebrates ${ }^{(4,5)}$. There is thus a clear match between a motoneuron's position in the cord and its target identity.

Motoneurons appear to develop their target specificity early, before their axons extend into the periphery, as shown by experiments that challenged misplaced neurons to find their targets ${ }^{(6,7)}$. Since neurons from individual pools can compensate for misplacement by correcting their trajectories, they must be specified with information enabling them to detect and respond to specific navigational cues. Additional experiments have shown that such navigational cues do exist, and that major classes of them correspond to the columnar organization within the cord ${ }^{(8,9)}$. For example, axons from the $\mathrm{MMC}_{m}$ diverge dor- sally from the spinal nerve path toward their target in response to a target-related cue; this cue is ignored by neighboring axons with other target specificities ${ }^{(10)}$. Likewise, axons from the lateral motor column segregate into dorsally and ventrally directed populations in response to local cues at the base of the limb $b^{(11-14)}$.

\section{The LIM homeobox genes}

Landmesser, in her landmark paper of $1978^{(2)}$ suggested that 'some feature of the motoneuron related to its position may be of importance in achieving the specific projection patterns observed'. Sixteen years later we have an indication of what this feature may be at the molecular level. A recent report by Tsuchida et al.(1) shows unique combinations of LIM-family homeobox gene expression that could define groups of motoneurons with like target identities.

Any expression patterns correlating with target identity would excite developmental neurobiologists. The Tsuchida et al.(1) report is particularly exciting because the LIM genes are putative regulatory genes; they could control expression of the properties required for specific navigation and innervation. The LIM (named for the genes $\underline{l i n}$ 1 , isl-1, mec-3) gene products have features typical of transcription regulators, including metal-binding sites ${ }^{(15)}$ and a homeodomain, and possess a unique pair of cysteine-rich motifs (the LIM-motif) ${ }^{(16-18)}$. Members of the LIM family have been implicated in other systems in specifying cell fate (e.g. refs 18 and 19) and basic body organization $(20,21)$. More relevant are indications that these genes 


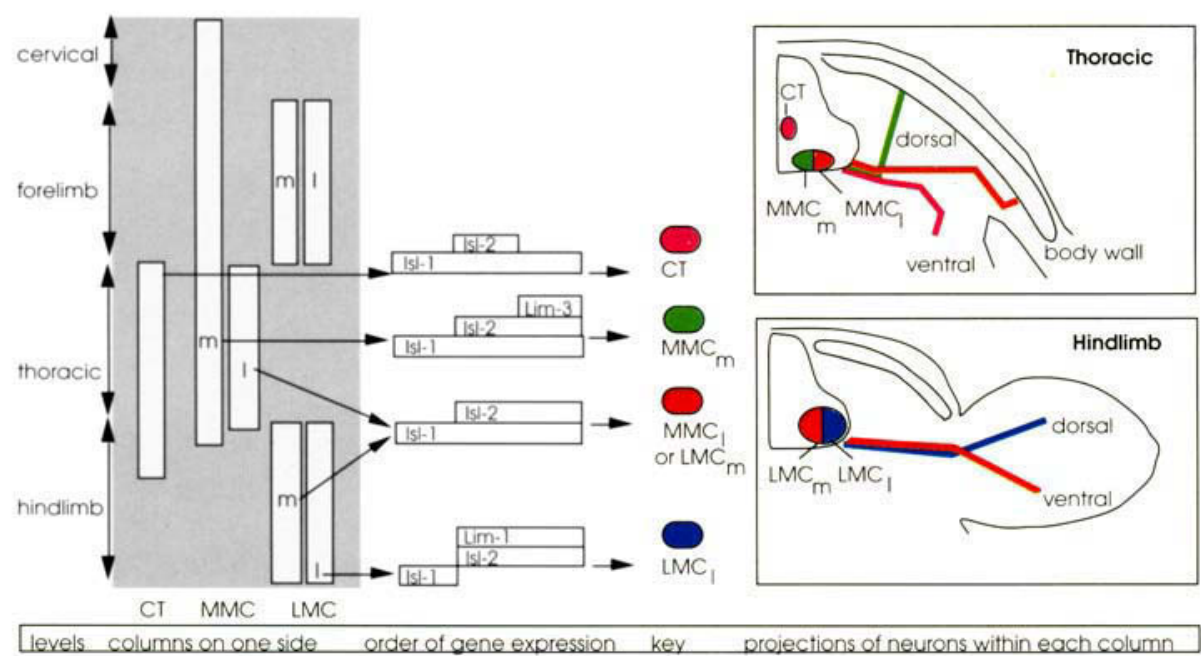

Fig. 1. Motor column organization, LIM family gene expression and projection patterns in the avian spinal cord. On each side of the spinal cord, motoneurons are clustered into columns that have a characteristic placement along the cranial-caudal axis (left). Neurons in these columns express distinctive combinations of LIM family genes (center). All express is $1-1$ and isl-2, which distinguishes them from other spinal cord neurons. Two columns are further distinguished by unique genes, LIM-3 in $M M C_{m}$ and $L I M-1$ in $L M C_{l}$, while a differential timing of is/-2 expression distinguishes two other groups. Neurons within each column make similar pathfinding decisions and project to targets of like embryonic origin (right). Thus, the column of Terni (CT) projects ventrally to sympathetic ganglia, the medial motor column (MMC) projects to axial muscles and the lateral motor column (LMC) projects to limb muscles. These columns are further subdivided: medial $(\mathrm{m})$ and lateral (1) subdivisions project in agreement with the dorsal-ventral positions of their targets. $M M C$ axons diverge from the spinal nerve to dorsal (MMC $m$ ) and ventral $\left(M_{M M C_{1}}\right)$ targets. At the base of the limb. $L M C_{1}$ axons turn dorsally while $L M C_{m}$ neurons turn ventrally. Note that two columns with non-overlapping distribution along the cranial-caudal axis, the $\mathrm{MMC}_{\mid}$and $\mathrm{LMC}_{\mathrm{m}}$, share the same expression pattern and both project ventrally. After Tschuida et al. ${ }^{(1)}$.

can specify subpopulations. For instance, the Drosophila ap gene apparently specifies a subset of abdominal muscles and has therefore been suggested to help determine the identity of muscle targets ${ }^{(22)}$.

\section{LIM genes and motoneuron specificity}

Prior work using antibodies in the chick suggested that the LIM gene islet-1 specifies motoneurons as a class(23). Motoneurons express islet-1 soon after their last division and before expressing other markers for their phenotype. When cells were experimentally induced to form motoneurons they expressed islet-1 and other motoneuron markers.

Tsuchida et al.(1) expand the putative role of LIM genes from merely determining motoneuron fate to defining their target specificity. They confirmed using in situ hybridization that all early chick motoneurons express islet-1. After about four days of development, however, they began to see subpatterns of expression suggesting the existence of a different but closely related protein, which they characterized, islet-2. Spurred on by this discovery, they cloned chick homologues to several other LIM family genes and found that two, Lim-1 and Lim-3, are also expressed by subpopulations of motoneurons. Thus, four different LIM family genes (islet-1, islet-2, Lim-1 and Lim-3) are now known to be expressed by motoneurons in the developing chick spinal cord.

These LIM genes could specify target identity because specific combinations of expression correlate with motoneuron topography. The code is combinatorial rather than one-to-one (Fig. 1). For example, while all neurons in the medial motor column express both islet-1 and islet-2, only those neurons in the $\mathrm{MMC}_{\mathrm{m}}$ express $\mathrm{Lim}-3$, thus distinguishing neurons in this column from those in all other motor columns. Lim-1, on the other hand, is expressed only in $\mathrm{LMC}_{\text {| }}$ neurons. Similar combinatorial expression of homeobox genes may specify segmental units of the developing brain (reviewed in refs 24 and 25).

The topography in the cord is itself only a correlate of target identity that is derived from previously defined maps of projection patterns. Tsuchida et al.(1) provide a clearer link with target identity by mapping projections directly. They labeled neurons from their peripheral targets and asked if the label coincided with expression patterns. It did. For example, when a dorsal limb muscle is injected with a tracer that is transported back to the innervating cell bodies, all neurons with the tracer express genes appropriate for the dorsal muscle group. Therefore, LIM gene expression correlates both with position and with innervation patterns.

As scientists, we delight in the exception that proves the rule. The exception in this case is a pool that is apparently misplaced. As a rule, axial muscles are innervated by $M M C_{m}$ neurons, except for the rhomboideus muscle, which is innervated by $L M C_{\text {, }}$ neurons. Does the gene expression pattern in these neurons agree with their position or with their target identity? If it agrees with the position, we might suspect that the genes are relevant to column formation but irrelevant to target identity. However, when the rhomboideus neurons were identified by injecting their muscle with tracer, they were found to express LIM genes typical of $M M C_{m}$ neurons. Thus, the combination of LIM genes expressed accurately predicts the target specificity.

\section{Vol. 17 no. 5 BioEssays}




\section{Development of columns and specificity}

Are these genes expressed before axons actually choose specific pathways or targets? The question is difficult to answer because the topography is itself late to arise. During the period when axons are busily choosing their pathways, the motoneurons are mixed within the spinal cord. The neuron's physical relationships are thus useless for showing if early expression patterns define motoneuron groups. All motoneurons could express all LIM genes, with the precise combinations sorting out only after all the interesting segregation into columns and target homing was done. Tsuchida et al.(1) provide evidence that early expression patterns are not inconsistent with defining roles. Subsets of motoneurons do express unique patterns of LIM genes even as they are migrating from the proliferative zones to prospective motor column sites and perhaps before they chose between major pathways. However, the identity of individual neurons is hard to define precisely during these stages. Direct correlations must thus await the discovery of other markers of target identity. In the future, it will be particularly interesting to determine directly whether specific expression precedes the very early pathfinding decisions made along the dorsal-ventral axis, since these decisions agree most closely with column identity.

It is particularly intriguing that these genes do not define individual motor pools but instead are expressed in columns, where the neurons all share major target-related features. This topographic specificity of motor columns and their targets is preserved in many animals ${ }^{(2-5)}$, suggesting important features of this organization are conserved, perhaps because they are major units of specification. Within a column, neurons all innervate like groups of muscles and make the same major pathfinding decisions, such as whether to take a dorsal or ventral path to the limb. Moreover, the decisions that differentially characterize each column are arguably the most central in navigating to the proper target. For instance, neurons are seldom able to correct their trajectory and reach an appropriate target if a manipulation causes them to chose the wrong dorsalventral path ${ }^{(11-13)}$. In contrast, neurons more readily correct when their cranial-caudal position is altered within a column ${ }^{(6,8)}$. Similarly, the medial-lateral column positions (which correspond to dorsal-ventral decisions) seldom differ among species, whereas cranial-caudal positions can vary even between individuals of a species(5). The dorsal-ventral pathfinding decisions also correlate with differences in target origins. Medial and lateral motor columns innervate axial and limb muscles respectively. $L M C_{1}$ and $L_{M C}$ innervate limb muscles derived from different embryological groups of pre-muscle tissue, the dorsal and ventral muscle masses. If the LIM genes do specify target identity, they do so in agreement with the most major pathfinding decisions and the most global differences in target organization.

\section{Future directions}

Tsuchida et al.(1) demonstrate that the differential expression of LIM family genes by motoneurons predicts their broad target specificity. At the very least then, these expression patterns represent very early markers for different motoneuron populations. Whether these genes actually determine target specificity is still an open question, however, since this study is purely correlative. Experimental evidence, such as an analysis of LIM mutants, is clearly desirable. These authors' findings should also inspire a search for genes that confer other aspects of target specificity. For instance, as-yet-unidentified genes may determine the target identities of individual pools. At a regional level of organization, differential identities develop early(26), but we have no idea what distinguishes thoracic groups from the evolutionarily later limb groups. Since the LIM family is believed to code for proteins that regulate transcription, another obvious question is the identity of the downstream genes. Implicit in the suggestion that LIM genes determine target specificity is that they determine the differential responses of motoneurons to guidance cues, perhaps by regulating expression of cell surface receptors or adhesion molecules. Such molecules must be expressed before pathfinding commences, and could thus mark target identity early. In short, the present results herald a new era in the study of motoneuron identity.

\section{References}

1 Tsuchida, T., Ensini, M., Morton, S.B., Baldasarre, M., Edlund, T., Jessell, T.M. and Pfaff, S.L. (1994). Topographic organization of embryonic motor neurons defined by expression of LIM homeobox genes. Cell 79, 957970.

2 Landmesser, L. (1978). The development of motor projection patterns in the chick hind limb. J. Physiol. 284, 391-414.

3 Hollyday, M. (1980). Organization of motor pools in the chick lumbar lateral motor column. J. Comp. Neurol. 194, 143-170.

4 Fetcho, J.R. (1987). A review of the organization and evolution of motoneurons innervating the axial musculature of vertebrates. Brain Res. Rev 12, 243-280.

5 Tyrell, S., Schroeter, S., Coulter, L. and Tosney, K.W. (1990). Distribution and projection pattern of motoneurons that innervate hindlimb muscles in the quail. J. Comp. Neurol. 298, 413-430.

6 Lance-Jones, C. and Landmesser, L. (1980). Motoneurone projection patterns in the chick hindlimb following early partial reversals of the spinal cord. J. Physiol. 302, 581-602.

7 Eisen, J.S. (1994). Development of motoneuronal phenotype. Annu. Rev. Neurosci. 17, 1-30.

8 Lance-Jones, C. and Landmesser, L. (1981). Pathway selection by embryonic chick motoneurons in an experimentally altered environment. Proc. R. Soc. Lond. (B) $214,19-52$.

9 Tosney, K.W. (1992). Growth cone navigation in the proximal environment of the chick embryo. In The Nerve Growth Cone (ed. P.C. Letourneau, S.B. Kater and E.R. Macagno), pp 387-403. Raven Press, New York.

\section{BioEssays Vol. 17 no. 5}


10 Tosney, K.W. (1987). Proximal tissues and patterned neurite outgrowth at the lumbosacral level of the chick embryo: deletion of the dermamyotome. Dev. Biol, 122, 540-588.

11 Fergusen, B. (1983). Development of motor innervation of the chick following dorsal-ventral limb bud rotation. J. Neurosci. 3, 1760-1772.

12 Lance-Jones, C. (1986). Motoneuron projection patterns in chick embryonic limbs with a double complement of dorsal thigh musculature. Dev. Biol. 116, 387-406.

13 Whitelaw, V. and Hollyday, M. (1983). Neural pathway constraints in the motor innervation of the chick hindlimb following dorsoventral rotations of distal limb segments. J. Neurosci. 3, 1226-1233.

14 Tosney, K.W. and Landmesser, L.T. (1984). Pattern and specificity of axonal outgrowth following varying degrees of chick limb bud ablation. $J$. Neurosci. 10, 2518-2527.

15 Li, P.M., Reichert, J., Freyd, G., Horvitz, H.R. and Walsh, C.T. (1991). The LIM region of a presumptive Caenorhabditis elegans transcription factor is an iron-sulfur and zinc-containing metallodomain. Proc. Natl Acad. Sci. USA 88 9210-9213.

16 Freyd, G., Kim, S.K. and Horvitz, H.R. (1990). Novel cysteine-rich motif and homeodomain in the product of the Caenorhabditis elegans cell lineage gene lin-11. Nature 344, 876-879.

17 Karlsson, O., Thor, S., Norberg, T., Ohlsson, H. and Edlund, T. (1990), Insulin gene enhancer binding protein is 1 i is a member of a novel class of proteins containing both a homeo- and a Cys-His domain. Nature 344, 879-882. 18 Way, J.C. and Chalfie, M. (1988). mec-3, a homeobox-containing gene that specifies differentiation of the touch receptor neurons in $C$. elegans. Cel/54, 5 16.

19 Ferguson, E.L., Sternberg, P.W. and Horvitz, H.R. (1987). A genetic pathway for the specification of the vulval cell lineages of Caenorhabditis elegans. Nature 326, 259-267.
20 Taira, M., Jamrich, M., Good, P.J. and Dawid, I. (1992). The LIM domaincontaining homeobox gene XIIm-1 is expressed specifically in the organizer region of Xenopus gastrula embryos. Genes Dev. 6, 356-366.

21 Barnes, J.D., Crosby, J.L., Jones, M., Wright, C.V.E. and Hogan, B.L.M. (1994). Embryonic expression of Lim-1, the mouse homolog of Xenopus Xlim1 , suggests a role in lateral mesoderm differentiation and neurogenesis. Dev. Biol. 161, 168-178.

22 Bourgouin, C., Lundgren, S.E. and Thomas, J.B. (1992). apterous is a Drosophila LIM domain gene required for the development of a subset of embryonic muscles. Neuron 9, 549-561.

23 Ericson, J., Thor, S., Edlund, T., Jessell, T.J. and Yamada, T. (1992). Early stages of motor neuron differentiation revealed by expression of homeobox gene islet-1. Science 256, 1555-1560.

24 McGinnis, W. and Krumlauf, R. (1992). Homeobox genes and axial patterning. Cell 68, 283-302.

25 Puelles, L. and Rubenstein, J.L.R. (1993). Expression patterns of homeobox and other putative regulatory genes in the embryonic mouse forebrain suggests a neuromeric organization. Trends Neurosci. 16, 472-479.

26 O'Brien, M.K., Landmesser, L. and Oppenheim, R.W. (1990). Development and survival of thoracic motoneurons and hindlimb musculature following transplantation of the thoracic neural tube of the lumbar region in the chick embryo: functional aspects. J. Neurobiol. 21, 341-355.

Kathryn W. Tosney and Kevin B. Hotary are at the Biology Department, The University of Michigan, Ann Arbor, MI 481091048, USA and Cynthia Lance-Jones is at the Department of Neurobiology, The University of Pittsburgh, School of Medicine, Pittsburgh, PA 15261, USA. 